\title{
NUESTRA AMÉRICA EN LA ENCRUCIJADA. LAS REVOLUCIONES CONOSUREÑAS ENTRAN EN ZONA DE TURBULENCIA
}

\author{
ARMANDO BARTRA \\ Universidad Autónoma Metropolitana, Xochimilco
}

Recepción manuscrito: 4 de enero de 2015

Aceptación versión final: 8 de marzo de 2015

\begin{abstract}
RESUMEN La caída de los precios de las commodities socava la estrategia con que los gobiernos progresistas de América Latina han hecho de las rentas recuperadas mediante nacionalizaciones la palanca redistributiva de revoluciones de bienestar legitimadas a través de comicios ¿Cuáles son los desafíos políticos y económicos que plantea el nuevo contexto?

PALABRAS CLAVE Renta, materias primas, redistribución, revoluciones de bienestar, extractivismo.
\end{abstract}

ABSTRACT The fall in commodities' prices undermines the strategy with which the progressive governments of Latin America have turned the income recovered through nationalization into the redistributing lever of welfare revolutions legitimated by public elections. What are the new political and economic challenges posed by the new context?

KEYWORDS Income, raw materials, redistribution, welfare revolutions, extractivism.

CODIFICACIÓN JEL E6, F1, I38, N56, N96, 054.

\section{INTRODUCCIÓN}

No nos basta condenar la realidad, queremos transformarla.

Tal vez esto nos obligue a reducir nuestro ideal; pero nos enseñará, en todo caso, el único modo de realizarlo.

J. C. Mariátegui

Por tres lustros las mudanzas progresistas ocurridas en algunos países sudamericanos contaron con un ambiente macroeconómico propicio, de modo que la recuperación para los Estados de la soberanía y las rentas antes cedidas se tradujo en una pronta reducción de la inequidad social lograda mediante políticas redistributivas, y dio lugar a una inédita generación de lo que llamo «revoluciones de bienestar». 
En 2008 se interrumpió la onda expansiva y paulatinamente las materias primas se fueron abaratando. Luego, al reanudarse lentamente el crecimiento en las economías centrales, los capitales que habían llegado atraídos por las posibilidades de inversión y/o altas tasas de interés empezaron a refluir y las deudas contraídas a tasas bajas y respaldadas por los recursos exportables se encarecieron al tiempo que estos se abarataban. De esta manera, la relativa holgura está dejando paso a la estrechez y con ello forzando los recortes al gasto público y la austeridad. Cambio de época que hace patente no necesariamente la impertinencia, pero sí los límites de la dimensión primario-exportadora del modelo de desarrollo elegido, ubicando a los procesos trasformadores latinoamericanos en una nueva y difícil etapa en que las mudanzas necesarias difícilmente traerán los beneficios inmediatos que se lograron en la fase anterior. Pasar de revoluciones de bienestar a revoluciones de austeridad. Este es el reto.

\section{TRIPLE FIN DE CICLO: NEOLIBERALISMO, CAPITALISMO, MODERNIDAD}

Al alba del tercer milenio la gran crisis pone en cuestión al neoliberalismo, al capitalismo y a la modernidad occidental llevándonos a una época de transición en que tendremos que ir desechando estructuras civilizatorias de larga data. Sin embargo, el colapso tiene un desarrollo desigual.

En nuestra América lo que ya se desacreditó es el modelo neoliberal, erosionando la hegemonía sistémica y fortaleciendo al emergente bloque opositor; una convergencia de excluidos y explotados, pero también de capas medias y hasta de empresarios vapuleados por la apertura desordenada de los mercados, la especulación financiera y las megacorporaciones abusivas. El dispositivo para el cambio es, pues, una amplia alianza antineoliberal. Y si tomamos en cuenta en lo internacional la desaparición del «campo socialista» y en lo nacional la pobreza de nuestros pueblos y lo variopinto del sujeto contrahegemónico, habremos de concluir que en el corto plazo la mudanza conducirá a alguna variante de capitalismo posneoliberal: economías de mercado estatalmente reguladas y democráticamente redistributivas que no inhiben la acumulación, pero sí la explotación extrema del trabajo, la discriminación étnica y el saqueo de la naturaleza. Economías abiertas que no dan las espaldas a la globalidad, pero que buscan un mejor acomodo en ella y cuyo horizonte es aún el de la modernidad en sus grandes vertientes: economía de mercado capitalista, economía planificada socialista y como palanca alguna clase de desarrollo. Lo dice bien la constitución boliviana: «economía plural», con protagonismo del Estado y prioridad estratégica de la producción social y comunitaria. ¿Abigarrado? Sí. Pero es que en un quimérico subcontinente de ayllus y trasnacionales, sólo con ejercicios grotescos resistiremos la globalidad imperial y saldremos del capitalismo disforme que nos tocó.

En las condiciones globales y nacionales prevalecientes se puede acotar al mercado y a los empresarios, pero no prescindir de ellos. ¿El riesgo? Que en vez de que la vida se vaya desmercantilizando; regresen las privatizaciones; que en vez de que la producción se vaya subordinando al interés social y a satisfacer necesidades reales, prime la lógica de la acumulación; que en lugar de que los empresarios tengan un sitio en la concertación, devengan actores protagónicos gérmenes de renovadas oligarquías... En trances como este, en que la inercia 
de las estructuras juega contra los propósitos libertarios y justicieros, nada está definido de antemano y todo depende de la conducción y la direccionalidad que se le dé al proceso.

\section{DE VIENTO DE COLA A ZONA DE TURBULENCIAS}

Vistas en la perspectiva de tres lustros, las revoluciones conosureñas son fractales: rupturas que desembocan en cursos inéditos y muy diversos de los modelos acuñados durante el siglo $\mathrm{XX}$ por los países que transitaron al socialismo. En lo político se apoyan en una combinación relativamente incruenta de movimientos sociales ascendentes y triunfos electorales reiterados, que les han dado continuidad sin necesidad de cancelar el pluralismo y haciendo de ellas mudanzas hasta ahora de baja conflictividad si las comparamos con las sangrientas confrontaciones en que desembocaron casi todas las revoluciones de la pasada centuria. En lo económico se encontraron apenas al despegar con lo que el expresidente de Uruguay Pepe Mujica llama «viento de cola»: economía mundial en expansión y precios altos de los bienes primarios que exportamos, con lo que la decisión estratégica de recuperar rentas y la voluntad política de combatir redistributivamente la inequidad, tuvieron escenarios propicios, dando como resultado atípicas revoluciones de la bonanza y el bienestar. Holgura ciertamente relativa y coyuntural, pero contrastante con la estrechez en que se movieron las del siglo XX, que por décadas fueron revoluciones de austeridad y penuria, cuando no de hambruna y mortandad.

En lo que va del XXI, la izquierda conosureña está ganando elecciones y repitiendo en el gobierno. Y entre el bienestar procurado por la revolución y su continuidad por la vía comicial hay una relación directa, pues si el primer triunfo es un voto por la esperanza y de rechazo al orden establecido, los subsecuentes se asocian con los beneficios sociales, libertades políticas y cotas de autoestima y dignidad que los gobiernos progresistas hayan hecho posibles. La estrechez, la penuria y el acoso interno y externo crían autoritarismo, mientras que la tolerancia y el pluralismo democrático florecen mejor en la holgura y la estabilidad. En el bloque histórico impulsor de las conversiones antineoliberales conosureñas se descentra a los empresarios nacionales y a las trasnacionales, pero no se los excluye. Así, la izquierda que hoy gobierna en Bolivia pudo primero desequilibrar y achicar a la derecha económica, después derrotarla políticamente y finalmente meterla al redil obligándola a entrar al juego de la revolución, porque - aun si acotados - parte de los intereses que representa tienen cabida en el nuevo modelo, y si este es exitoso también ellos ganan.

Estos son activos del curso seguido. Los pasivos están en que el cambio operado: rescate de los recursos naturales y sus rentas, gestión estatal de sectores decisivos de la economía y firmes políticas redistributivas son un golpe de timón pero, aun si la contrarrestan, no erradican la lógica económica del capitalismo. No soy de los que piensan que lo único «revolucionario» es cambiar el «modo de producción» y la gente que se joda. Lo que pasa es que el modelo dio de sí y amaina el viento de cola, de modo que las revoluciones de la holgura están quedando atrás y los próximos pasos suponen cambios mayores en el paradigma socioeconómico. Lo que significa pasar de cursos recorridos en medio de relativa abundancia a mudanzas operadas en contextos de estrechez y austeridad. 


\section{EL PAPEL DE LAS RENTAS EN LAS REVOLUCIONES DE BIENESTAR}

En el capitalismo como en el socialismo - que aun si diversas son economías y por tanto sujetas a una férrea legalidad - sin crecimiento del «producto» no se puede redistribuir el «ingreso» ni reducir significativamente la inequidad. Ahora bien, en medio de una crisis global de escasez que dispara las rentas, el crecimiento más a la mano es el que se sustenta en una recuperación y valorización de los recursos naturales, en un proceso cuyo saldo es la reprimarización exportadora de la economía. Lo que, de no combinarse con cuidado ecológico y contrarrestarse con enérgicas políticas de fomento a la industrialización y producción de mercado interno, deviene en lo económico un círculo vicioso y en lo ambiental una trampa ecocida. En cuanto a la dimensión social y justiciera del desarrollo, es claro que para atenuar rápido la inequidad no hay como el gasto público en programas sociales. Dicho en pocas palabras: rescate de rentas por el Estado que las emplea para reducir la pobreza y aumentar el consumo de las capas medias, con lo que además el gobierno adquiere una legitimidad social que los críticos consideran clientelar. Fórmula útil en el corto plazo, pero contradictoria y a la larga insostenible, sobre todo cuando se encapota el escenario económico mundial.

El panorama es sin duda preocupante. Pero el atolladero al que nos encaminamos no resulta de la «traición» de quienes gobiernan, sino de que la recuperación y redistribución de rentas es la mejor receta disponible para ir saliendo del pantano que heredamos. Es lo que tenemos a la mano y por ahí hay que caminar hacia el futuro. Son atendibles los argumentos «postextractivistas» de Eduardo Gudynas, Alberto Acosta, Joan Martínez Allier, Raúl Prada, Edgardo Lander, Maristella Svampa y otros, pero me parece que de poco sirve clamar contra el neodesarrollismo populista, clientelar, extractivista y primario-exportador sin asumir íntegramente los retos que imponen las circunstancias. Un contexto complicado que explica el porqué de los recurrentes controles y estatizaciones venezolanas, que suenan a viejo socialismo, mientras Cuba amplia el campo de la producción mercantil; que explica por qué el vicepresidente de Bolivia hablaba del nuevo «capitalismo andino-amazónico» y el presidente de Ecuador apuesta por un «capitalismo eficiente»; que explica la propensión de los gobiernos de la región a poner en valor porciones de la selva amazónica; que explica las alianzas estratégicas con China. Aunque para pasar de explicar a justificar, habría primero que ponderar las opciones.

Lo cierto es que en lo económico lo que impulsan los gobiernos progresistas del subcontinente es un capitalismo algo más endógeno que el de antes, marcadamente redistributivo, con fuerte participación estatal y asociado a países y bloques de repuesto. Modelo renco, disforme y a mediano plazo insostenible pero que en el corto ha mejoró sensiblemente la vida de la gente. Lo que no es poca cosa. Sobre todo si tenemos en mientes las hambrunas y penurias en que se abismaron las revoluciones socialistas del XX.

Resumiendo: adoptar como estrategia de desarrollo la exportación de bienes primarios es un grave error cuyo costo ya conocemos, pues en nuestra América es recurrente. Pero también lo hubiera sido no aprovechar tácticamente una situación excepcional en los términos del intercambio centro-periferia, términos que para nosotros casi siempre habían sido desfavorables. Sacar provecho de un corto lapso de altas cotizaciones que permitió 
revertir en alguna medida la pobreza, desarrollar algo la infraestructura productiva y social, y capitalizar a otros sectores de la economía. Oportunidad que, sin embargo, llegó a su fin.

\section{REINVENTANDO BOLIVIA}

Bolivia es un buen ejemplo de las revoluciones de bienestar conosureñas. El país andino amazónico no es sólo un Estado plurinacional que reconoce su diversidad de pueblos y culturas, es también una economía de la diversidad que admite la pluralidad técnica, productiva y social. Paradigma que supone la coexistencia de dos racionalidades: la de la ganancia y la del buen vivir, en una complementariedad dinámica donde lo que está en juego es si a la postre la lógica del lucro dominará sobre la del bienestar y los trabajadores seguirán explotados o si por el contrario conducirá a un orden socioeconómico inédito donde impere la economía moral.

La combinación de políticas pertinentes y contexto global bonancible ha dejado un saldo positivo. Según la Cepal, entre 2006 y 2010 la economía creció a un promedio anual de casi $5 \%$, y aun en el nefasto 2009 la expansión fue de 3,4\%. A lo que se añade un superávit de la balanza de pagos de 326 millones de dólares y un incremento en las reservas internacionales, que para 2010 llegaban a 10 mil millones. En el mismo lapso, el salario mínimo tuvo un incremento de 54,3\%, lo que añadido a la baja tasa inflacionaria significó un importante mejoramiento del nivel de vida (Fernández, 2010, pp. 7-8). Pero los indicadores macroeconómicos solos no hacen verano y la pregunta sobre la direccionalidad del proceso sigue en el aire. Los analistas coinciden en que durante los gobiernos del Movimiento al Socialismo (MAS) el histórico sesgo primario-exportador de la economía boliviana se ha profundizado (Aillón, 2012, p. 103) y algunos sostienen que «el sector de hidrocarburos en Bolivia no es un sector predominantemente estatizado, sino un sector predominantemente transnacionalizado» (Orellana, 2012, p. 62).

Si en lo político la revolución boliviana es un combate por viabilizar la plurinacionalidad, en lo económico la batalla es por el destino de la renta. Y el saldo ha sido favorable. «Este crecimiento económico y las nuevas ganancias han posibilitado importantes marcos de acción sociopolíticos, que en primer lugar deben llegar a la población más pobre y vulnerable, y que son financiados por una gran parte de la renta» (Radhuber, 2010, pp. 75-79). La reelección de Evo Morales y García Linera en los comicios de 2014 con un holgado 60\%, indica que si bien sólo el 30\% de los bolivianos dice estar satisfecho con el comportamiento de la economía (Uzeda, 2013, pp. 64-65), la mayoría aprueba el sentido que le imprime el gobierno del MAS.

\section{CAÍDA Y VOLATILIDAD DE LAS MATERIAS PRIMAS, UN DESAFÍO}

«Bolivia vive de su gas, pero también de su minería», escribió su vicepresidente (García, 2013, p. 32). Y algo semejante podría decir la mayor parte de los países conosureños, tanto los de gobiernos progresistas como los conservadores. Lamentablemente, como lo proclama la consultora Merrill Lynch, «las materias primas han caído fuertemente en desgracia». Según el Banco Mundial durante la segunda mitad de 2014 los precios de las materias primas energéticas retrocedieron 30\% (en diciembre la caída fue aún mayor), las agrícolas 13\% y los metales 
10\%. Y los pronósticos son negativos: según Economist Intelligence Unit «los vientos en contra que ha enfrentado América Latina en 2013-2014 persistirán en 2014. Esperamos que la mayoría de los precios de los productos primarios caerá en 2015» (Economic Intelligence Unit, 2010, pp. 12-14).

El petróleo, que desde fines del pasado siglo tuvo cotizaciones ascendentes en gran medida debido a la demanda creciente de economías emergentes como China e India, se había depreciado en 2008, cuando el Brent de referencia cayó de 137 a 35 dólares el barril, pero después se recuperó manteniéndose ligeramente por encima de los 100 dólares entre 2011 y 2013, hasta que en diciembre de 2014 cayó por debajo de los 60 dólares, cotización en la que el Brent se mantiene a principios de 2015 cuando escribo esto. El colapso ha de ubicarse en la previa apreciación de los hidrocarburos, sustentada en demanda creciente y progresivo agotamiento de los yacimientos más fértiles. Tendencia estructural que marca el fin de la época la de los combustibles fósiles baratos, palanca del moderno capitalismo industrial. Pero hay factores que pueden contrarrestar temporalmente esta tendencial apreciación: descubrimiento de más yacimientos y nuevas técnicas de extracción, por el lado de la oferta; mayor eficiencia en el uso de los combustibles y menor crecimiento económico, por el lado de la demanda. Lo que confluyó en 2014 provocando un desplome de alrededor del 50\% en el precio del crudo. Todo hace pensar que la sobreoferta que está detrás de la caída se mantendrá por un tiempo, pues es difícil que las inversiones físicas ya hechas se retiren. Sin embargo, es poco probable que se hagan nuevas, sobre todo en el petróleo-gas fracking estadounidense, la mitad de cuyos campos no son rentables con cotizaciones por debajo de los 60 dólares.

En este marco juegan a las vencidas potencias petroleras y megacorporaciones mientras que las agencias imperiales aprovechan la oportunidad para desestabilizar a países exsocialistas como Rusia y «socialistas del siglo XXI» como Venezuela, cuyas finanzas públicas están altamente petrolizadas. Pero, pase lo que pase, no hay que perder de vista que al irse agotando el petróleo fácil se desploma la eficiencia energética de los combustibles fósiles — que cada vez cuesta más sacar- y que aun a 60 dólares la cotización del crudo es hoy el doble de lo que era hace tres lustros. Tendencia a la apreciación con altibajos pero duradera que vale también para otros bienes primarios. «Pese a los descensos — sostiene Economic Intelligence Unit—, los precios (de metales y productos agrícolas) se mantienen el doble más o menos, de sus niveles de finales de la década de 1990, y el incremento de las poblaciones y de los ingresos de los mercados emergentes les dará algún sustento» (Economic Intelligence Unit, 2010, pp. 12-14).

La conclusión es que estratégicamente los recursos naturales se enrarecen, de modo que por razones ecológicas y económicas lo prudente es conservarlos; mientras que tácticamente la especulación volatiliza sus cotizaciones, de modo que lo prudente es no depender demasiado de ellos. Sin embargo, el hecho es que hasta ahora las revoluciones de bienestar han sostenido su relativa holgura valorizando bienes no renovables.

\section{EL RIESGO DE PONER TODOS LOS HUEVOS EN LA MISMA CANASTA}

Bolivia ilustra bien el curso adoptado por los países conosureños de gobierno progresista. La capacidad económica del gobierno del MAS se sustenta en que los hidrocarburos se 
nacionalizaron en 2006, de modo que de los 223 millones de dólares en impuestos que pagaba esta industria en 2000, se pasó a 2235 millones de dólares en 2010. Pero lo más espectacular ocurrió en minería, donde han crecido producción, precio y captación estatal. En 2000 se extraían 400 mil toneladas y en 2010 un millón, mientras que el valor de la producción pasó de 426 millones de dólares a 2400 millones y la captación estatal de 9,5 millones de dólares a 305 millones. Sin embargo, aunque históricamente elevados, los precios del estaño bajaron en 2008, con lo que lo captado por el Estado se redujo a la mitad, y disminuyeron de nuevo en 2013. (García, 2013, p. 32)

En diciembre de 2014, y a pregunta expresa sobre el posible tránsito de una revolución de bienestar a una revolución con estrechez, el vicepresidente García Linera me decía que sí, que la boliviana había disfrutado de cierta holgura dada la onda expansiva de la economía mundial y la apreciación de las commodities, pero que eso se terminaba y había que estar preparados para la austeridad. Sin embargo, sostuvo también que - indio al fin-el Presidente Evo Morales es austero y acostumbra hacer guardaditos en previsión de los años de vacas flacas. De modo que si bien Bolivia no tiene un fondo petrolero soberano como Arabia Saudita o Noruega, sí tiene reservas internacionales por $10 \mathrm{mil} \mathrm{millones,} \mathrm{lo} \mathrm{que} \mathrm{re-}$ presenta el 50\% del PIB. Y que pese a las presiones de mineros para que en parte se destinaran a salarios, las reservas sólo se emplean en proyectos productivos. Dijo, igualmente, que es política del gobierno no tocar los fondos de pensiones. Y que sí, que el país depende en lo externo de la exportación del gas y del estaño, pero que hay proyectos en curso para industrializar los bienes primarios, además de que la mitad del crecimiento de la economía se sostiene en el mercado interno. Algo parecido había argumentado en 2011:

Es probable que, de acuerdo al contexto internacional, haya una fluctuación de los precios de minerales que nos puede afectar, y la clave para afrontar esta situación es más volumen de mineral y mejor tecnología; es decir, producir más y volver más eficiente el trabajo. (García, 2013, p. 23)

Lo que es verdad. Pero también lo es que más pronto que tarde se impondrá un cambio de modelo hacia otro en que la disponibilidad de recursos naturales no marque el destino del país, en que Bolivia ya no "viva de su gas y de su minería». Y me temo que este tránsito será más imperioso pero difícil ahora, cuando las revoluciones del Cono Sur ya no volarán con viento de cola. Pero Bolivia no es más que un ejemplo, y no el más extremo. Venezuela es precursora de los cambios que se viven en el cono sur y hace ya 16 años que empezó a desmarcarse del neoliberalismo. Sin embargo, el país será golpeado como pocos por el desplome de los precios del petróleo: en 2014, cuando apenas empezaban a caer, la producción retrocedió ahí 2,3\%, la inflación fue de $64 \%$ y el año terminó con el presupuesto público y el tipo de cambio colgados de alfileres. Porque el petróleo representa el $96 \%$ de las exportaciones de Venezuela y el crudo es un aceite adictivo de cuya dependencia no se ha podido librar en tres lustros de revolución bolivariana. El problema está en que si bien las políticas redistributivas del presidente Hugo Chávez redujeron la desigualdad social y la pobreza, que para 2012 ya sólo afectaba al 25\% de la población, a partir de ese año volvió a aumentar y para 2013 ya era pobre el 32\% de los venezolanos. 
A Brasil le está pegando la caída de los precios del hierro y de la soya, de modo que por primera vez en 14 años en 2014 la balanza comercial - sin considerar la de pagos - tuvo un déficit de casi 4 mil millones de dólares. De hecho, la bonanza en el gigante del Cono Sur terminó antes, pues mientras que entre 2003 y 2010 - con Lula en el gobierno- la economía creció a un promedio de $4 \%$ anual y salieron de la pobreza millones de brasileños, en el primer mandato de Dilma Rousseff, el crecimiento promedio fue de sólo 1,6\%. Puede haber torpeza en el gabinete económico de Dilma como hubo habilidad en el de Lula. Pero el fondo no es ese. Y también Ecuador tuvo en 2014 un déficit de 127 millones de dólares en la balanza comercial, a resultas del menor precio del petróleo.

Los países de curso económico más conservador no escapan de la turbulencia. Perú tuvo en 2014 el mayor déficit comercial de su historia: 2550 millones de dólares, por la caída de las cotizaciones de los metales que constituyen el 60\% de sus exportaciones. En el mismo año, el déficit en la balanza comercial de Colombia fue de 4807 millones de dólares, por el desplome de los precios del petróleo y el carbón.

A la baja de los precios de las commodities se añade el previsible fin del dinero barato, pues los bancos centrales de los países desarrollados, que desde 2008 bajaron las tasas de interés para sacar a sus economías de la recesión, han anunciado su intención de elevarlas. El problema está en que los países primario-exportadores acumularon deuda a tasas bajas y respaldada en su disponibilidad de los entonces muy cotizados recursos naturales, materias primas cuyas cotizaciones ahora disminuyen al tiempo que disminuye su demanda, mientras que las tasas de interés aumentan. El encarecimiento del dinero en estos países también se debe a que por el diferencial de tasas de interés y el estrechamiento de las posibilidades de inversión en los países centrales, muchos capitales se refugiaron en América Latina, pero ahora comienzan a refluir en la medida en que disminuyen las ventajas que antes ofrecían.

Otro efecto negativo del modelo es que la entrada de divisas apreció la moneda de estos países y en consecuencia abarató las importaciones, provocando que el incremento en la demanda interna de bienes de consumo final resultante de las políticas redistributivas, se orientara a productos importados, debilitando aún más a las industrias locales que debían haber sido uno de los ejes que permitiera salir del círculo vicioso del llamado extractivismo. La dependencia respecto de las exportaciones azucareras es ancestral en Cuba y se mantuvo después de la revolución, aunque a partir de ese momento, uncida a los países del bloque socialista. El modelo de desarrollo sustentado en la caña y su procesamiento se derrumba hace 25 años cuando la isla se ve obligada a transitar de una mono exportación del edulcorante a precios estables y artificialmente favorables para Cuba, a un escenario de precios bajos del azúcar y precios altos de las importaciones. Los caribeños emprenden entonces una complicada transición, que el bloqueo imperial hace aún más difícil y que cinco lustros después sigue en curso. En la inauguración de la cumbre económica de la Comunidad de Estados Latinoamericanos y Caribeños (Celac), celebrada en La Habana en enero de 2014, Raúl Castro dirigiéndose a sus hermanos y primos conosureños, colgados aun de las commodities, resumió la dolorosa experiencia isleña en una frase lapidaria que debiera ser escuchada: «Hemos padecido el problema de no haber traducido los períodos 
de altos precios de los productos naturales que se exportan en procesos de desarrollo de largo plazo» (Sánchez, 2014, p. 30). Lo padeció Cuba, lo están padeciendo los demás.

\section{UN ESPINOSO DILEMA POLÍTICO}

El fin de la bonanza que sostuvo a las revoluciones comiciales de bienestar haciendo posible que una y otra vez se legitimaran en los comicios, mete una cuña en el hasta ahora sólido ensamble entre pluralismo político electoralmente resuelto y revolución económica y social de largo aliento. Al combinarse la estrechez financiera con el cerco político imperial y la ofensiva de la derecha interna, se ve comprometido el pluralismo o se ve comprometida la revolución. Y en realidad se ven comprometidos ambos, porque a estas alturas sin alguna clase de pluralismo político no hay revolución que valga.

El contexto en el que hay que ubicar el dilema es el acoso al que están sometidos los gobiernos progresistas de la región por las oligarquías locales y las potencias imperiales. Poderes otrora hegemónicos y hoy revanchistas que disponen de los recursos necesarios para agudizar artificialmente el impacto negativo del cambio en el contexto económico, que controlan la mayor parte de los medios de información masiva y que están dispuestos a todo con tal de revertir los procesos emancipadores conosureños. Hay, además, numerosas evidencias de que el núcleo duro de la derecha latinoamericana es golpista, como lo ejemplifican los casos exitosos de Honduras y Paraguay, y los fracasados de Venezuela y Ecuador. También las hay, de que emplea la calumnia, el sabotaje, el terrorismo y la violencia para desestabilizar a los gobiernos progresistas.

En la medida en que el impulso social con que arrancaron los cambios se mantuvo en la mayor parte de los países que asumieron estrategias de desarrollo posneoliberales, y que la combinación de recuperación de rentas, política redistributiva y contexto macroeconómico favorable permitió incrementar y sostener el bienestar de la población, fue posible también contrarrestar el hostigamiento de la derecha sin restringir la democracia. Sin embargo, cuando esto falte o se debilite es posible que crezca la tentación de defender la revolución por otros medios.

Que quede claro, democracia no es permisividad ni mucho menos claudicación. Los gobiernos progresistas han ejercido la autoridad que les dan los votos y el apoyo social del que disponen para someter, incluso mediante la violencia legítima, a las oposiciones de derecha que se saltan las trancas. Lo han hecho en Bolivia los gobiernos del MAS contra los exabruptos de los «varones de la media luna» y lo han hecho en Venezuela los gobiernos del Partido Socialista Unificado contra los excesos de los sectores más duros de la Mesa de Unidad Democrática. No hay que confundir la firmeza con el autoritarismo; sin embargo, la línea está ahí y puede traspasarse. Al respecto dijo el siempre directo Pepe Mujica en una de sus últimas entrevistas como presidente:

Mirá el resultado humano y práctico que han tenido los experimentos apurados, «definitivos» de socialismo: al final tuvieron menos que repartir ( $y$ fueron antidemocráticos) porque cuando se te achica todo, tenés que caer en la ferocidad represiva. (Gabetta, 2015, p. 23) 
Posiblemente don Pepe estaba pensando en el «socialismo real» del siglo XX, pero el hecho es que también a los progresistas latinoamericanos del tercer milenio se les «achica todo». Es verdad, sin embargo, que una revolución que no se defiende es una revolución que se pierde. La restauración del viejo orden puede seguir una vía formalmente democrática en que la derecha regresa al poder legitimada por los comicios, como en los casos de Nicaragua y Chile, o adoptar una vía golpista, como en los casos de Honduras y Paraguay, aunque en estos dos países después de un interregno abiertamente neoliberal la izquierda ha regresado al gobierno. ¿Es inevitable que revoluciones que no se hicieron a tiros tengan que preservarse a tiros? Pienso que no. El reto para las nuevas izquierdas radica en redefinir las alianzas, prioridades, ritmos, tiempos, estrategias y tácticas, necesarios para sostener revoluciones visionarias y radicales, pero democráticas y políticamente pluralistas. Revoluciones en donde no se gobierna en nombre de la «historia», el «proletariado» o el «pueblo», sino de las plurales mayorías ciudadanas y de los variopintos movimientos que las ponen en acción. El fondo del asunto está en hacer de la democracia un paradigma político, no de los socialdemócratas que desde hace rato la adoptaron, sino de la nueva izquierda radical y anticapitalista a la que no siempre se le da.

Lo que demanda no solo asumirla, sino repensarla. A las «dictaduras de clase» no se las sustituye con liberalismo clásico, ciudadanías indistintas y representantes «populares» que en los comicios se venden como mercancías, sino con ciudadanías diferenciadas, dialogantes, activas y organizadas; es decir, con un nuevo pluralismo que reconozca no sólo la diversidad política e ideológica, sino también la social, cultural e identitaria; una democracia radicalizada que asuma las elecciones y el gobierno de las mayorías, pero también las asambleas y los consensos; una democracia a la vez representativa y directa. El dilema entre la continuidad y persistencia necesarias para operar las profundas mudanzas estructurales que definen a las izquierdas y la discontinuidad implícita en la alternancia política en el gobierno, se resuelve en la creación socialmente consensada de instituciones que vayan más allá de los posibles cambios en la administración pública. Instituciones que son leyes, como las que surgieron de las paradigmáticas refundaciones constitucionales de Venezuela, Ecuador y Bolivia; pero también instituciones no estatales en sentido estricto. Instituciones sociales que operan en concordancia-discordancia con los gobiernos. Pienso en gremios, movimientos, organizaciones civiles, grupos académicos, asociaciones profesionales, medios de comunicación y toda clase de colectivos y comunidades.

Y lo que hay detrás de las instituciones sociales es cultura, cultura política en el sentido amplio del término. Lo que le da continuidad a un proyecto más allá de las fluctuaciones de los gobiernos, es que se vuelva hegemónico. Que no sólo sea adoptado por la mayoría, sino que algunos de sus ejes sean asumidos también por las minorías, que devengan «sentido común» en la acepción gramsciana del término. El desafío de izquierdas que posiblemente gobiernen intermitentemente no está — como estuvo antes - en que aprendamos a ser contrahegemónicos, sino en que nos enseñemos a ser hegemónicos sin dejar de ser inconformes y críticos. Lo que sólo es posible manteniendo el diálogo interno y la negociación con los antagonistas y los discrepantes, sin pretender que por ello ya no sean antagonistas o discrepantes. Para transitar de revoluciones de bienestar a las que el viento de cola 
infló las velas, a revoluciones austeras capaces de navegar en zona de turbulencias sin dejar de ser pluralistas y democráticas, lo que hace falta es volver hegemónico el altermundismo, es hacer de la utopía sentido común. Y en eso estamos.

\section{REFERENCIAS}

Aillón Gómez, T. (2012). La redistribución del excedente del sector hidrocarburos dentro de la estrategia de poder del Movimiento al Socialismo. Cochabamba, Bolivia: Universidad Mayor de San Simón.

Aillón Gómez, T. (2013). Nuevo paradigma de política económica y acumulación de capital industrial en la era del MAS. Búsqueda, 23(42), 81-116.

Economist Intelligence Unit (2014, diciembre 23). Petroprecios crean incertidumbre. La Jornada, 22.

Fernández-Vega, C. (2010, agosto 7). México S. A. La Jornada, 26.

García Linera, Á. (2013). Las empresas del estado. Patrimonio colectivo del pueblo boliviano. La Paz, Bolivia: Vicepresidencia del Estado Plurinacional.

Gabetta, C. (2015, febrero 22-23). El capitalismo ya está agotado, sentencia Mujica. La Jornada, 2.

Mariátegui, J. C. (1969). Ideología y política. Lima, Perú: Editorial Amauta.

Orellana Aillón, L. (2012). Regulación y acumulación de capital en el sector de hidrocarburos (1998-2011), Cochabamba, Bolivia: Universidad Mayor de San Simón.

Radhuber, I. (2010). Rediseñando el Estado: un análisis a partir de la política hidrocarburífera en Bolivia. Umbrales, (20), 105-125.

Sánchez Rebolledo, A. (2014, enero 30). Dos discursos. Una coincidencia. La Jornada, 22.

Uzeda Vázquez, A. (2013). El «proceso de cambio» siete años después. Búsqueda 23(42), 58-80.

Villazón del Carpio, O. E. (2013). Valoración económica de los recursos naturales e histórica dependencia boliviana. Búsqueda, 23(41), 9-35. 
